\title{
EFFECT OF NACL ON NEUTRON FLUX DENSITY IN GRAPHITE BLOCK
}

\author{
Tomáš SlančíK, Kamil ŠTevanka* \\ Brno University of Technology, Faculty of Electrical Engineering and Communication, Technická 10, 61600 \\ Brno, Czech Republic \\ * corresponding author: kamil.stevanka@vutbr.cz
}

Abstract. Aim of this work is to study the effect of $\mathrm{NaCl}$ on neutron flux through graphite block. Graphite block had 39 channels drilled through it and filled with $\mathrm{NaCl}$. Au and In foils and In wire was used for neutron activation measurement of the neutron flux. AmBe neutron source with nominal activity of $92.5 \mathrm{GBq}$ was used. The results were compared with MCNP simulations with channels filled with salt and air. Twelve different locations for Au and In foils were used and In wires were place in three locations to measure vertical profile of neutron flux.

KEYwORDS: HPGe, $\mathrm{NaCl}$, chloride salts, neutron flux.

\section{INTRODUCTION}

Molten salts were first considered for application in nuclear reactors in late 1940s as part of the Aircraft Reactor Experiment. Molten salts were chosen because of the high power density requirements for the reactor and multiple other reasons [1, 2]. The research continued with Molten Salt Reactor Experiment (MSRE), which was considered a success [3, 4]. However the research of MSRs was discontinued after MSRE due to other priorities, lack of funding and other political reasons [5]. Since fluorides were chosen as primary coolant, most of the research to date focused on these mixtures [1, 3. Nevertheless chlorides were considered as well and therefore some $\mathrm{Cl}$ based mixtures were studied too [2].

Main advantages of MSRs compared to PWRs are higher fuel burn-up, higher operating temperature and low operating pressure usually around $0.3 \mathrm{MPa}$. There is also theoretical possibility of breeding fuel from both uranium and thorium. Among the challenges are higher neutron flux, corrosive behavior of salts, more difficult maintenance and inspection $\underline{6}$.

The interest in MSRs was renewed in 21st century. Even though most concepts are based on fluorides, some concepts, especially fast reactors, rely on chloride mixtures. Among the concepts that plan to utilize chlorides are MSFR by Terrapower, LLC and SSR by Moltex Energy Ltd [7, 8]. Apart from usage in MSRs, chlorides can also be used in accelerator-driven systems 9 .

Since the data for neutronics of chlorides are not as well studied as fluorides, the goal of the work was to construct the experimental setup and determine how the $\mathrm{NaCl}$ affects neutron flux density and to determine whether the experiment provides any useful data. This experiment was conceived to be the first in the series of experiments aimed at gathering more data about chloride neutronics.

\section{EXPERIMENTAL SETUP}

The equipment used for the experiment consisted of graphite block, AmBe neutron source, sodium chloride and golden and indium threshold activation detectors (TAD).

Dimensions of the graphite block were $506 \times 300 \times$ $300 \mathrm{~mm}$ (length $\mathrm{x}$ width $\mathrm{x}$ height). Altogether 39 channels were drilled all the way through the block, these were filled with $\mathrm{NaCl}$. One hole was drilled at the center of the shorter side of the block to accommodate neutron source. This hole was drilled to the depth of $175 \mathrm{~mm}$. The layout of the channels can be seen in Figure 1. The diameter of the $\mathrm{NaCl}$ channels was $29.3 \mathrm{~mm}$ and the diameter of neutron source hole was $22 \mathrm{~mm}$.

The block was placed on the $5 \mathrm{~mm}$ thick steel plate, which was attached to $600 \mathrm{~mm}$ tall wooden base.

AmBe neutron source with neutron emissivity of $5.6 \cdot 10^{6} \mathrm{~s}^{-1}$ was used. It is made of $833 \mathrm{mg}$ of $\mathrm{AmO}_{2}$ and $7374 \mathrm{mg}$ of ${ }^{9} \mathrm{Be}$ encased in stainless steel cylinder which has diameter of $19.1 \mathrm{~mm}$ and height of $48.6 \mathrm{~mm}$.

\section{Methodology}

Preliminary calculations were made to determine suitable diameter. Eventually it was decided to drill channels with diameter of $29 \mathrm{~mm}$ based on the practical feasibility. The $29 \mathrm{~mm}$ drill was the largest readily available and smaller diameters would mean more channels which would be time consuming. One channel took about 20 minutes to drill.

Due to the concerns about graphite fragility it was decided that distance between edge of the holes and the block should be at least $15 \mathrm{~mm}$ and keeping sufficient distance between edges of holes meant that there would be actually less volume of salt if bigger diameter was used.

The channels are $0.3 \mathrm{~mm}$ wider due to drill vibrations. The hole for neutron source was drilled to the 


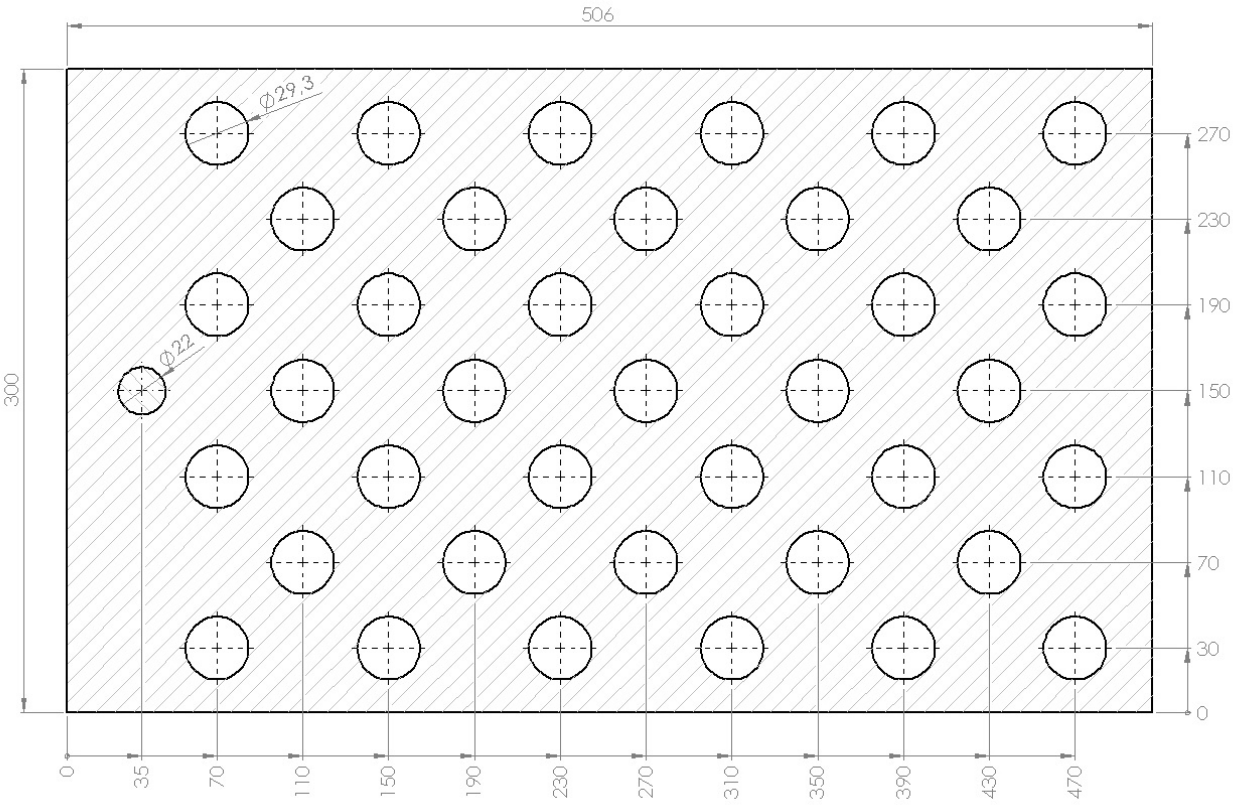

Figure 1. Layout of drilled channels.

depth of $175 \mathrm{~mm}$ in order to vertically center the source. SolidWorks 2014 software was used to create model of the block and the base. Each of the $29 \mathrm{~mm}$ channels was filled with $99.5 \%$ purity $\mathrm{NaCl}$ salt, the salt was put into polyethylene bag for easier manipulation.

Neutron activation measurement was used to measure the neutron flux density. ${ }^{197} \mathrm{Au}$ (Figure 4) and ${ }^{115}$ In (Figure 3 foils were used as activation detectors, which have high cross section for thermal neutron capture.

Foils were placed in paper wrap in the selected channels as seen in Figure 2 Foils were placed at the 3 o'clock side of the holes, approximate placement of the foils is designated by red dots in Figure 2 All of the In foils had same diameter of $16 \mathrm{~mm}$, thickness of $0.5 \mathrm{~mm}$ and $99.99 \%$ purity. Au foils had square shapes but their dimensions differed as can be seen in Table 1. Apart from the foils, In wires were used in channels II $\alpha, \mathrm{II} \gamma$ and II $\eta$, right in front of the neutron source. This was used to determine neutron flux over the entire height of the block. The diameter of In wire was $1 \mathrm{~mm}$ and length was $300 \mathrm{~mm}$.

The $\mathrm{Au}$ detectors were placed lower than $150 \mathrm{~mm}$ from the base and In detectors were placed above $150 \mathrm{~mm}$ because the foils could not be placed side by side in the vertical center of the channels at height of $150 \mathrm{~mm}$.

In addition to the detectors in the channels, other detectors were placed on the external sides of the block. Both $\mathrm{Au}$ and In detectors were placed in the center of the respective sides of the block. Detectors with cadmium shielding were added to the left and rear sides (From the source point of view) of the block to detect ratio between thermal and fast neutrons. In

\begin{tabular}{cccc}
\hline Hole & $\begin{array}{c}\text { Purity } \\
(\mathbf{\%})\end{array}$ & $\begin{array}{c}\text { Thickness } \\
(\mathbf{m m})\end{array}$ & $\begin{array}{c}\text { Dimensions } \\
(\mathbf{m m})\end{array}$ \\
\hline $\mathrm{II} \alpha$ & 99.95 & 0.25 & $10 \times 10$ \\
\hline $\mathrm{II} \gamma$ & 99.95 & 0.25 & $10 \times 10$ \\
\hline $\mathrm{II} \eta$ & 99.90 & 0.02 & $13 \times 13$ \\
\hline $3 \mathrm{~A}$ & 99.95 & 0.25 & $10 \times 10$ \\
\hline $3 \mathrm{C}$ & 99.90 & 0.02 & $13 \times 13$ \\
\hline $3 \mathrm{E}$ & 99.90 & 0.02 & $12 \times 12$ \\
\hline $\mathrm{III} \alpha$ & 99.95 & 0.25 & $10 \times 10$ \\
\hline $\mathrm{III} \gamma$ & 99.90 & 0.02 & $12 \times 12$ \\
\hline $\mathrm{III} \eta$ & 99.90 & 0.02 & $13 \times 13$ \\
\hline $4 \mathrm{~A}$ & 99.90 & 0.02 & $13 \times 13$ \\
\hline $4 \mathrm{C}$ & 99.90 & 0.02 & $12 \times 12$ \\
\hline $4 \mathrm{E}$ & 99.90 & 0.02 & $12 \times 12$ \\
\hline
\end{tabular}

TABLE 1. Au detectors characteristics.

foils had same dimensions as the ones in the channels and Au foils are described in Table 2

HPGe detector was used to measure activation of the foils. GAMWIN software was used to evaluate measurements.

The reaction rate $\mathrm{R}_{R C}$ (As seen in Equation 1) was calculated after the area of measured peaks was manually determined using results from GAMWIN software. Intensities and detector efficiency for designated gamma energies can be seen in Table 3 


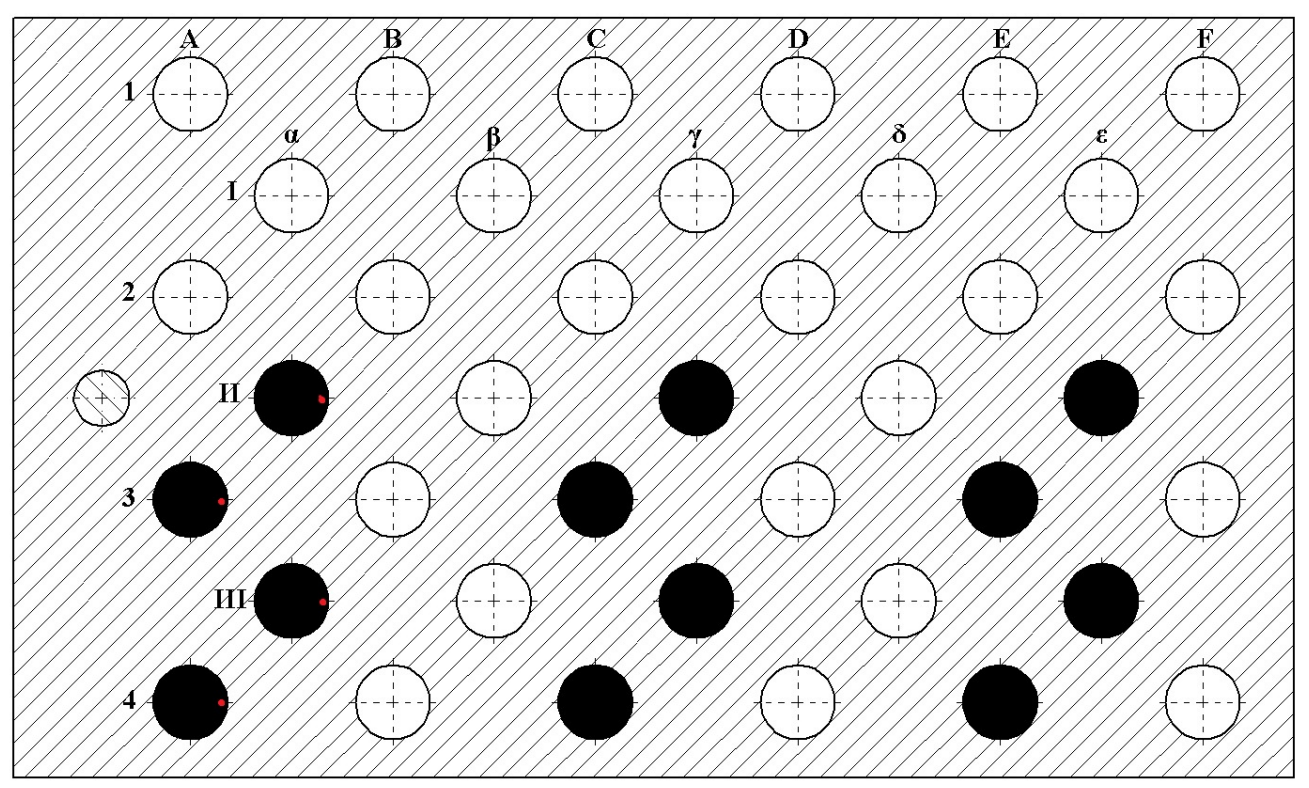

FiguRE 2. Layout of detectors.

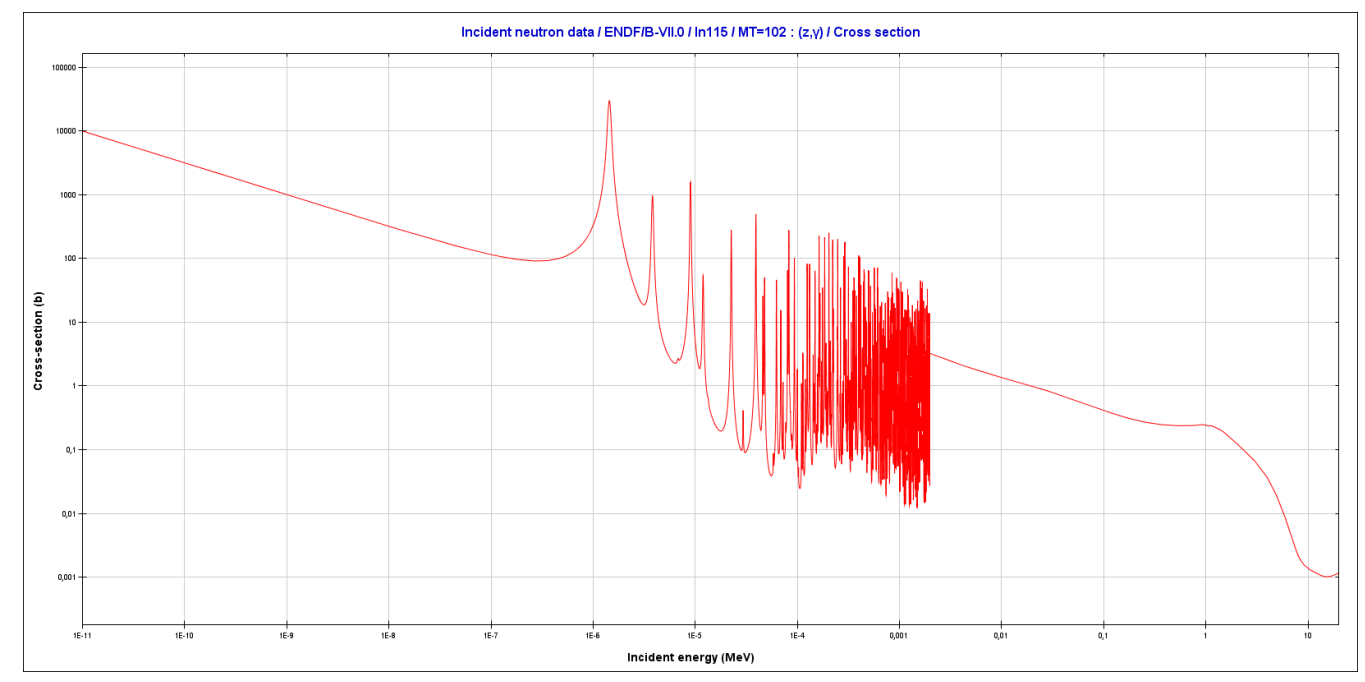

FIGURE 3. Indium-115 radiation capture cross-section [10].

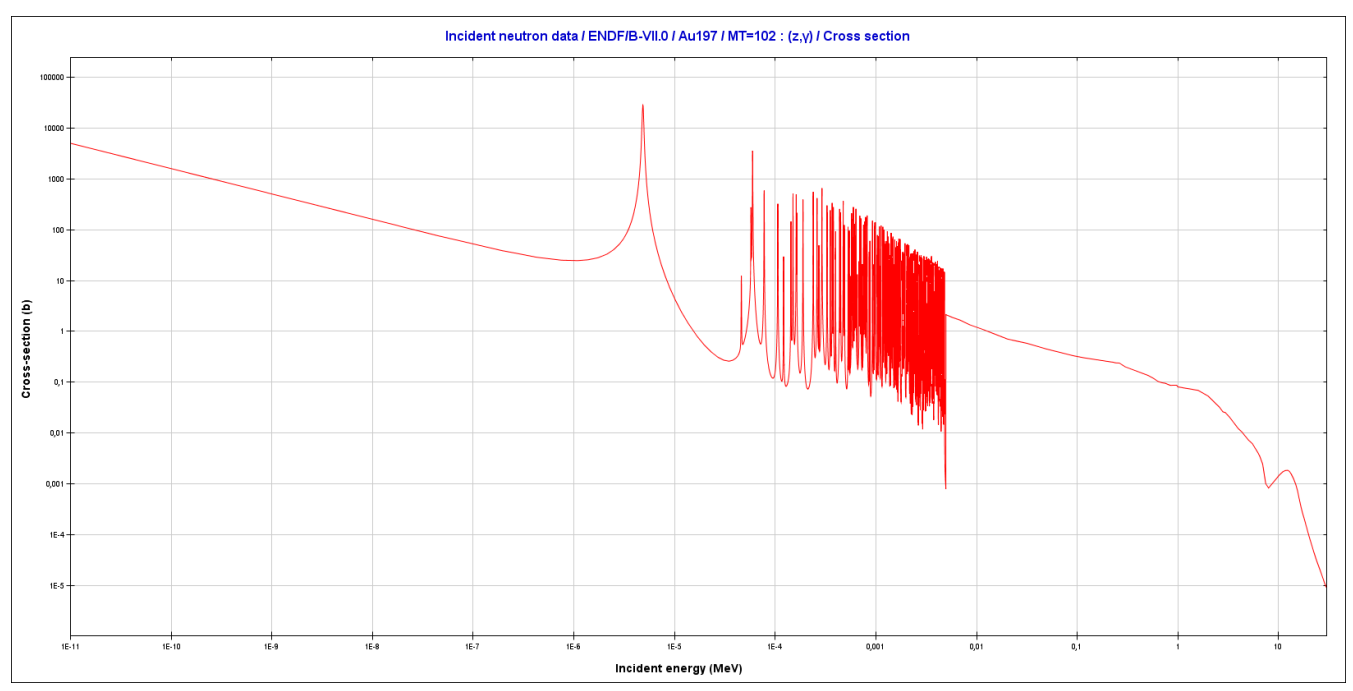

Figure 4. Au-197 radiation capture cross-section [10]. 


\begin{tabular}{cccc}
\hline Side & $\begin{array}{c}\text { Purity } \\
(\mathbf{\%})\end{array}$ & $\begin{array}{c}\text { Thickness } \\
(\mathbf{m m})\end{array}$ & $\begin{array}{c}\text { Dimensions } \\
(\mathbf{m m})\end{array}$ \\
\hline Source & 99.95 & 0.250 & $10 \times 10$ \\
\hline Left Cd & 99.95 & 0.250 & $25 \times 25$ \\
\hline Left & 99.95 & 0.125 & $25 \times 25$ \\
\hline Right & 99.95 & 0.125 & $25 \times 25$ \\
\hline Rear Cd & 99.95 & 0.500 & $25 \times 25$ \\
\hline Rear & 99.95 & 0.500 & $25 \times 25$ \\
\hline
\end{tabular}

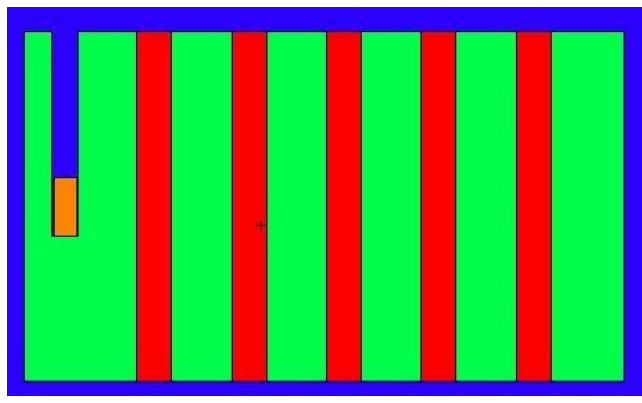

FiguRE 5. Vised visualisation.

\subsection{MCNP SIMULATION}

MCNP 6 was used to simulate the experiment [15]. Polyethylene was neglected in the model given that combined weight of the bags was approximately $100 \mathrm{~g}$ compared to the weight of the entire setup which was approximately $90 \mathrm{~kg}$. The model contained additional $300 \mathrm{~mm}$ thick wall on the side of neutron source, this could have some impact on the results. Activation detectors were not placed within the channels but simplified approach was taken which evaluated neutron flux density through designated sections of channels. Channels were separated into four sections, the two evaluated sections were at heights between 140 to $150 \mathrm{~mm}$ and $150-160 \mathrm{~mm}$. Then the reaction rate was calculated using calculated neutron fluxes, atomic density and cross sections of $\mathrm{Au}$ and In. Simulations were done for holes filled with air and $\mathrm{NaCl}$.

Where $S\left(E_{\gamma}\right)$ is area of measured peak of selected energy level, $\lambda$ is decay constant of particular isotope, $t_{\text {real }}$ is measuring time, $t_{\text {live }}$ live time of measurement, $\epsilon_{\gamma}\left(E_{\gamma}\right)$ is detector efficiency for given energy level, $I_{\gamma}\left(E_{\gamma}\right)$ is intensity of gamma line, $t_{i r r}$ is duration of irradiation and $t_{\text {delay }}$ is time between the end of irradiation and beginning of measurement.

Afterward the weighted average of reaction rates for different energies for In was calculated. Then reaction rates per gram of material was calculated using dimensions of detectors and densities of materials [1], [12, 13].

The irradiation lasted for 7 days and measuring intervals were 15 mins for In wire and 20 mins for In and $\mathrm{Au}$ foils. The irradiation lasted for 7 days to ensure sufficient degree of activation because half-life of ${ }^{198} \mathrm{Au}$ is 2.694 days 14 .

Because samples could not be reinserted into the setup without disrupting the experiment, it was not possible to conduct multiple measurements of the samples.

Reaction rates measured and calculated on outside detectors with and without cadmium shielding were used to calculate cadmium ratio 2

$$
r_{C d}=\frac{R_{r}}{R_{r}^{C d}}
$$

Where $R_{r}$ is reaction rate of all of the neutrons, $R_{r}^{C d}$ is reaction rate of fast neutrons

\section{Results}

The results of experiment and simulations can be seen in graphs Figure 6 to 13 Some results have substantial error margins, this is due to low intensity of neutron flux of neutron source and relatively short time of measurements. The short measuring time was caused by high number of samples because there was only one HPGe available. The measuring time could not be longer, because the activity of samples would decrease too much and the setup did not allow to reinsert foils.

Cadmium ratio in Table 4 shows that neutrons were not very well moderated, for future research would be useful to have higher volume of graphite.

As can be seen in the graphs Figure: 6 to 9 the trend of In foils is similar to MCNP simulation results, however most of the reaction rates are higher in the experimental samples than in simulations. This could be due to aforementioned simplifications and also due to high degree of uncertainties. The result for In foil in position $\alpha \mathrm{III}$ (Figure 8) is different, but the error margin for that sample is also substantial, therefore it cannot be concluded that the model is inconsistent with the experiment.

The results for golden foils of $0.02 \mathrm{~mm}$ thickness differ substantially from simulations because reference reaction rate was calculated for thickness of $0.25 \mathrm{~mm}$ in MCNP simulations. The experimental results for 


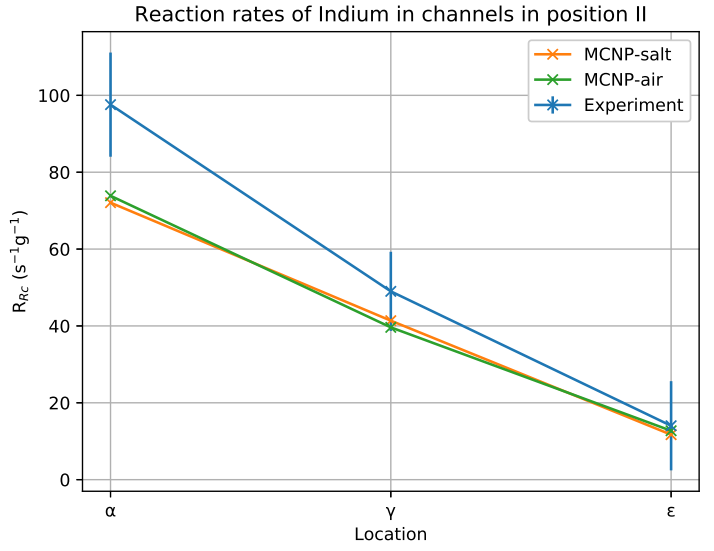

Figure 6. Results for In foils in positions II.

$0.25 \mathrm{~mm}$ thickness is much more similar to the simulation, whereas reaction rate for $0.02 \mathrm{~mm}$ is much higher, this is caused by self-shielding of the thicker foil material.

The difference between simulations with salt and air is not very pronounced. This is due to relatively small amount of salt in the system, however all simulations show slightly higher reaction rates for air in the farthest positions, indicating that $\mathrm{NaCl}$ captures small amount of the neutrons.

Wire measurements Figure 14, Figure 15, Figure 16 showed high degree of uncertainty because of short half-life of In wire and short measuring time. Each wire was divided into five segments, each $6 \mathrm{~cm}$ long. The wires could not be reinserted, therefore they were cut into 5 pieces due to short half-life [14] and these segments were measured. The first wire showed expected results with higher rate in the middle, other two wires showed different results with no clear trend. This was most likely caused by short measuring time, low activity of the samples farther from the neutron source and short half-life of Indium. The results for In wire are not reliable and require further measurements.

\begin{tabular}{ccc}
\hline \multirow{2}{*}{ Position } & Indium & Gold \\
\cline { 2 - 3 } & $\mathrm{r}_{C d}(-)$ & $\mathrm{r}_{C d}(-)$ \\
\hline Left & 1.4090 & 1.5579 \\
\hline Rear & 1.3243 & 1.6416 \\
\hline
\end{tabular}

TABLE 4. Experimental results.

\section{Conclusions}

The paper studies neutron flux density within graphite block with drilled channels that were filled with $\mathrm{NaCl}$. The aim of the work was to design and construct experimental setup and get some experience with chloride salts. Another goal was to see whether the MCNP

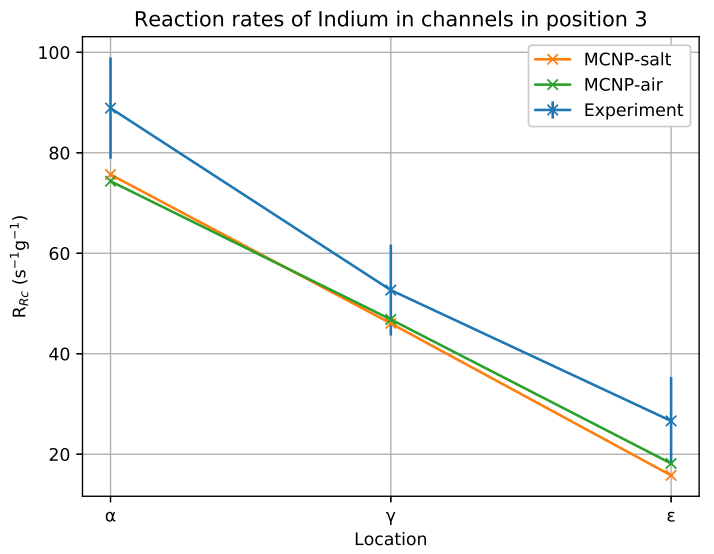

Figure 7. Results for In foils in positions 3.

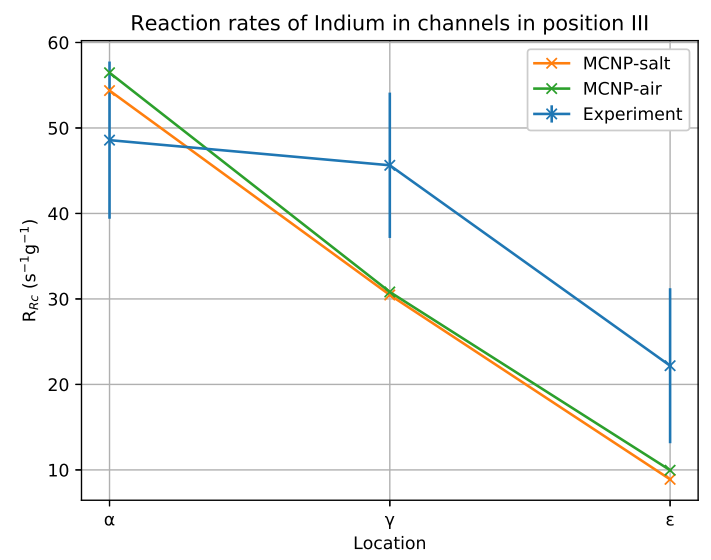

FiguRE 8. Results for In foils in positions III.

model is reasonably accurate compared to the experiment and to find out ways in which we could improve the experimental setup. The main purpose of the setup is to provide students with opportunity to measure and evaluate real life data and get hands on experience with scientific work. Neutron activation measurement was used to determine neutron flux. Twelve Au and In foils were used and three $30 \mathrm{~cm}$ long In wire were used as well. The wire measurement had high error margin due to short measuring time and only the wire at the closest position to the neutron source showed expected trend with regard to vertical distribution of neutron flux.

Both In and $\mathrm{Au}$ foils showed similar trends to the simulation, reaction rates were higher than those of the simulations in all cases except one and this could be attributed to measuring error. The self-shielding effect of gold affected the results significantly and measured values for thinner, $0.02 \mathrm{~mm}$ thick foils diverged from simulation considerably. This was caused by simulation input which used thicker $0.25 \mathrm{~mm}$ thick foils for normalisation.

Despite the fact that $0.02 \mathrm{~mm}$ foils showed significant divergence in values compared to model, it nevertheless showed similar trends. Given the error 


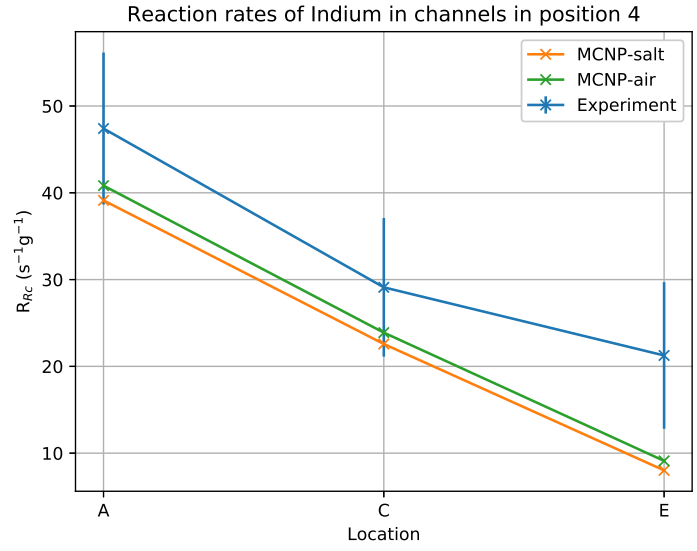

Figure 9. Results for In foils in positions 4.

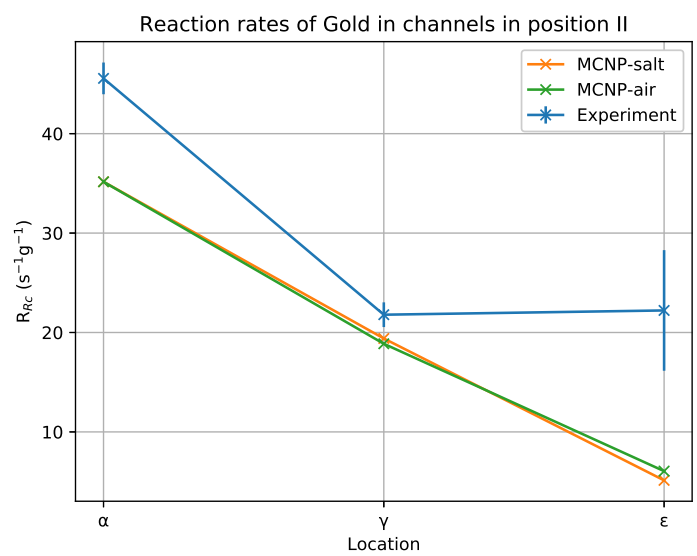

Figure 10. Results for Au foils in positions II.

margins it is sufficient indication that the model is in good agreement with the experiment.

The measuring errors were quite large, this was due to limitations of experimental setup which did not allow for reinsertion of the foils. This was particularly visible on In wires which were separated to 5 segments, but because of short half-life of indium could not be measured for a long time. In the future it is planned to upgrade the setup to allow for better manipulation of salt and also reinsertion of detectors.

The samples could not be reinserted because they were inserted simultaneously with the polyethylene bags. Once they were removed the polyethylene bag would not allow for the sample to be put back in. In the future it is planned to use vessels that could keep their shape, probably aluminium tubes. Thus allowing for continuous measurement. After the upgrade of the experimental setup it is planned to repeat the experiment, perform another experiment with empty channels to compare the results and adjust the MCNP model. It is also planned to measure the effects of other chloride salts, such as $\mathrm{LiCl}, \mathrm{KCl}, \mathrm{CaCl}_{2}, \mathrm{MgCl}_{2}$. It is also possible to add another layer, approximately $200 \mathrm{~mm}$ of graphite between neutron source and the block to get higher amount of thermal neutrons.

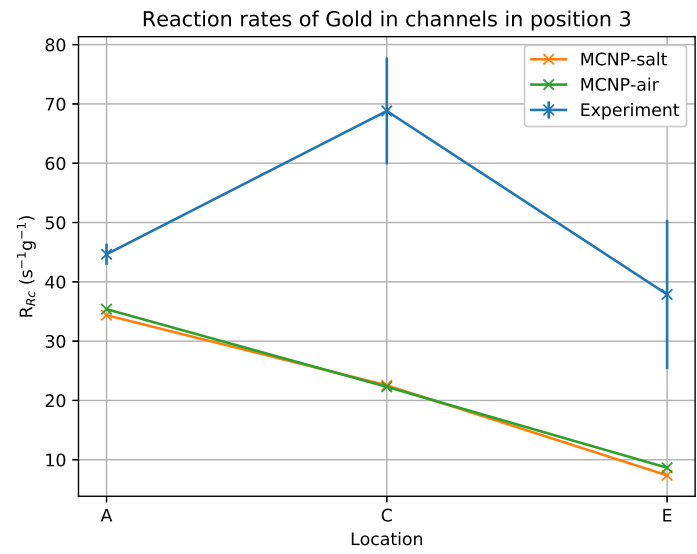

Figure 11. Results for Au foils in positions 3.

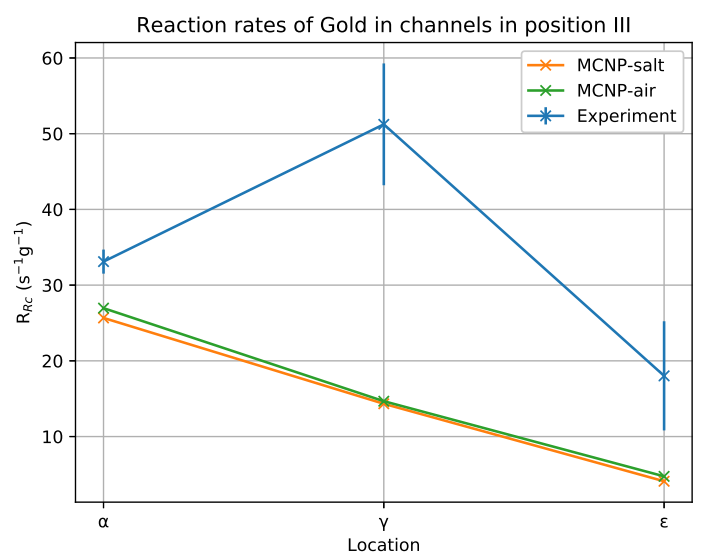

FiguRE 12. Results for $\mathrm{Au}$ foils in positions III.

\section{ACKNOWLEDGEMENTS}

The research was supported by project LTAUSA18198 and is part of cooperation between BUT and Texas A\&M University. Authors are thankful to their supervisor and PI of the project, Karel Katovsky, Ph.D., for his support and advice during the project.

\section{REFERENCES}

[1] W. Cottrell, H. Hungerford, J. Leslie, J. Meem. Operation of the Aircraft Reactor Experiment. ORNL -1845, Oak Ridge National Laboratory, 1955. http://large.stanford.edu/courses/2016/ph241/ dodaro1/docs/ornl-1845.pdf

[2] D. F. Williams, K. T. Clarno. Evaluation of salt coolants for reactor applications. Nuclear Technology 163(3):330-343, 2008. DOI:10.13182/nt08-a3992.

[3] R. Robertson. MSRE Design and Operations Report Description of Reactor Design. Ornl-tm-728, Oak Ridge National Laboratory, 1965.

http://moltensalt.org/references/static/ downloads/pdf/ORNL-TM-0728.pdf.

[4] M. Rosenthal, P. Kasten, R. Briggs. MOLTEN-SALT REACTORS - HISTORY, STATUS, AND

POTENTIAL. Nuclear Appliactions \&6 Technology 1969. http://moltensalt.org/references/static/ downloads/pdf/NAT_MSRintro.pdf 


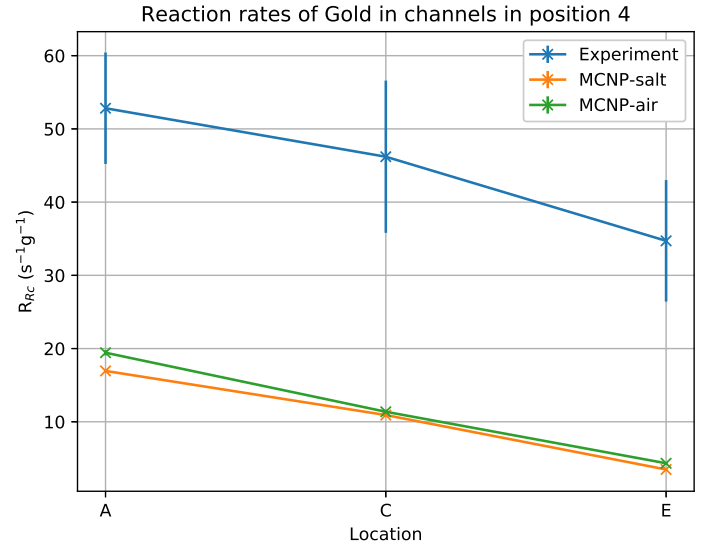

Figure 13. Results for Au foils in positions 4.

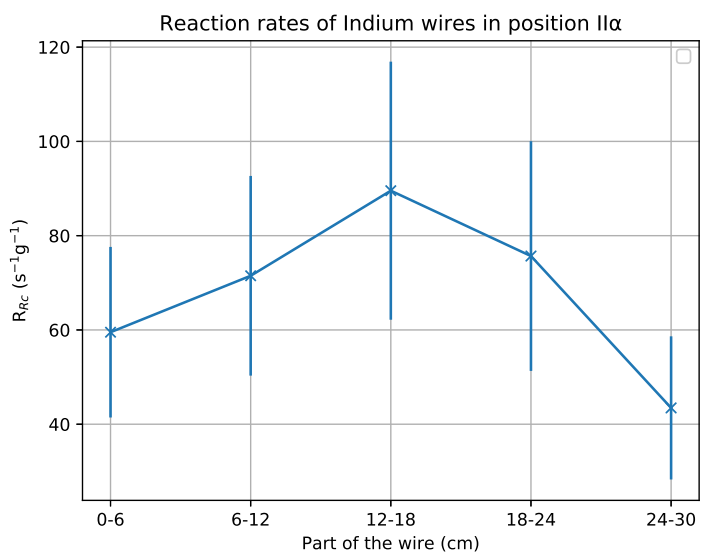

FiguRE 14. Results for In wire in position $\alpha$.

[5] B. Hoglund. Why the molten salt reactor (MSR) was not developed by the USA. Blogpost, 2010. http: //moltensalt.org/references/static/downloads/ pdf/WhyMSRsAbandonedORNLWeinbergsFiringV3.pdf

[6] D. E. Holcomb. Molten Salt Reactors Today Status \& Challenges. In Workshop on MSR Technologies Commemorating the 50th Anniversary of the Startup of the MSRE. ORNL, 2015.

https://public.ornl.gov/conferences/MSR2015/ pdf $/ 05$-Current $\% 20$ MSR $\% 20$ Status $\% 20$ and $\%$ 20Challenges_David\%20Holcomb.pdf

[7] World Nuclear Association - Molten Salt Reactors, 2018. http:

//www. world-nuclear.org/information-library/ current-and-future-generation/ molten-salt-reactors.aspx

[8] M. Elsa, H. Daniel, A. M., et al. Preliminary design assessment of the molten salt fast reactor. In European Nuclear Conference ENC2012. 2012.

[9] P. McIntyre, S. Assadi, K. Badgley, et al. Acceleratordriven subcritical fission in molten salt core: Closing the nuclear fuel cycle for green nuclear energy. In 22. international conference on application of accelerators in research and industry. AIP, 2013. DOI:10.1063/1.4802405

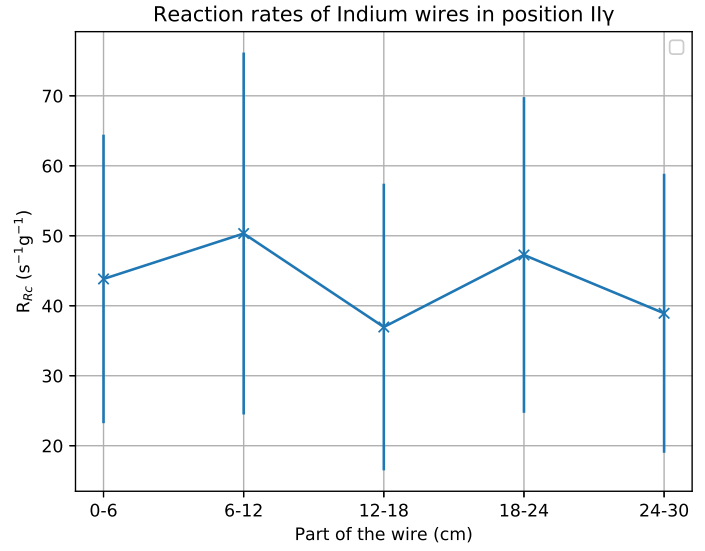

Figure 15. Results for In wire in position $\gamma$.

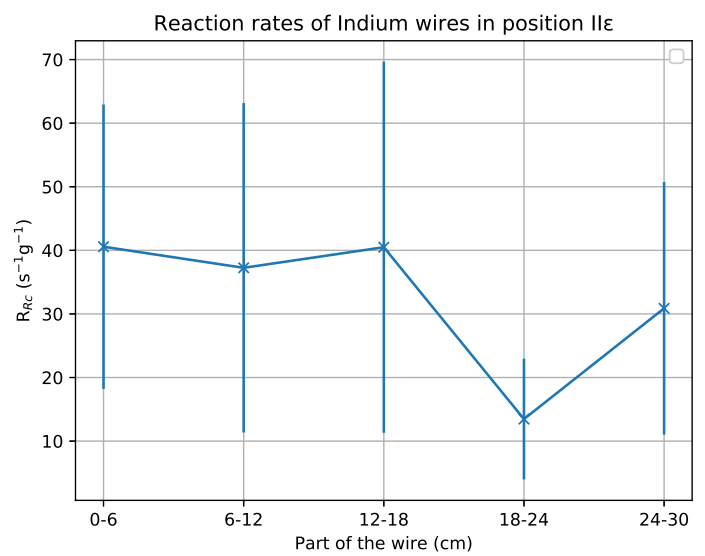

Figure 16. Results for In wire in position $\eta$.

[10] Nuclear Energy Agency - java-based Nuclear Data Information System, 2013. https://www. oecd-nea.org/janis/

[11] The Engineering Toolbox - Densities of common solids, 2019. https://www.engineeringtoolbox.com/ density-solids-d_1265.html

[12] The Engineering Toolbox - Metals and alloys densities, 2019. https://www.engineeringtoolbox. com/metal-alloys-densities-d_50.html

[13] K. Katovsky. Studium sekundarnich neutronu a jader vznikajicich pri reakcich protonu a neutronu $v$ tercich $z$ uranu a plutonia. Ph.D. thesis, [Czech], CVUT, 2008.

[14] NDS - IAEA - Live Chart of Nuclides, 2019. https://www-nds.iaea.org/relnsd/vcharthtml/ VChartHTML.html

[15] C. Werner. MCNP users manual - code version 6.2, 2017. https://mcnp.lanl.gov/mcnp_manual.shtml 